\title{
ALANINE - VALINE DYNAMICS IN PREGNANT RABBITS
}

\author{
TOWUANSE S. EMUDIANUGHE, BELLA KALDERON AND AVIVA LAPIDOT
}

${ }^{1}$ Department of Pharmacology and Therapeutics, Faculty of Health Sciences, University of Ilorin, Ilorin, Nigeria; ${ }^{2}$ Department of Isotope Research, Weizman Institute of Science, Rehovot, Israel

\begin{abstract}
$\left[{ }^{15} \mathrm{~N}\right]$-alanine and $\left[{ }^{15} \mathrm{~N}\right]$-valine dynamics were studied in 29 -30 days pregnant $\mathrm{New}$-Zealand rabbits. Over the experimental period, there was no detectable significant difference of mean $\pm S D$ of alanine concentrations within the sampling intervals in maternal, umbilical venous and arterial blood samples suggesting that alanine concentration was in a steady state and that the system was not being perturbed. Similar results were obtained for valine. The enrichment of alanine in the umbilical venous blood was $68.9 \pm 2.4 \%$ lower than that simultaneously obtained from the maternal vein $(P<0.05)$. A decrease of $42.7 \pm 4.7 \%$ in the umbilical arterial sample was observed compared to umbilical venous blood. The data suggest possible fetus production of alanine in utero. Both the maternal and foetal compartment were in isotopic steady state. Comparison of the enrichment of valine in the umbilical venous blood was $54.8 \pm$ $6.3 \%$ less than that of the maternal blood. Statistical comparison of the umbilical venous and arterial showed no significant difference. This suggests that there was no apparent valine production during the experimental period.
\end{abstract}

Keywords: Alanine, Valine, dynamics, fetus, pregnancy, rabbit

Correspondence (Current address): Department of Pharmacology and Therapeutic, Faculty of Health Sciences, University of llorin, Ilorin Nigeria

\section{INTRODUCTION}

The use of stable isotopes as a tracer in metabolic studies have generated more interest and resulted in accumulation of data which made it possible for a proper understanding of physiological conditions in both animal and human investigations. Over the past decade, series of investigations have been carried out on the protein and amino acid catabolism, amino acid production and synthesis using this tool (Lemmon al., 1976; Lemmon et al., 1979; Letto et al., 1986; Gilfillan et al, 1985; Kaihan et al, 1988).

Gilfihlan et al (1985) have suggested that the isotopic dilution occurring within foetal umbilical vein and arterial blood when $\left[{ }^{13} \mathrm{C}\right]$ alanine was infused in pregnant human subjects may be due to production, catabolism of amino acid and protein in the foetal muscle which may serve to transfer nitrogen from the foetal muscle to the liver for urea synthesis. Most studies have involved the infusion of one amino acid or with a carbohydrate especially glucose.

The present study was designed to find if the isotopic dilution was due to production or catabolism, see if administration of two amino acids will cause perturbation of the physiological conditions in pregnancy.

\section{MATERIALS AND METHODS}

$\left[{ }^{15} \mathrm{~N}\right]$-alanine and $\left[{ }^{15} \mathrm{~N}\right]$-valine were synthesized from ${ }^{15} \mathrm{NH}_{4} \mathrm{Cl}\left(90 \%{ }^{15} \mathrm{~N}\right.$-enriched) by the methods of Shermin (1946). The ${ }^{15} \mathrm{~N}$-alanine and ${ }^{15} \mathrm{~N}$ valine were $97 \%{ }^{5} \mathrm{~N}$-enriched and alanine:valine composition ratio was $4: 1$.

Animals and Procedures: New Zealand albino rabbits, 29-30 days pregnant and weighing between $4-4.75 \mathrm{~kg}$ were used in all experiments. The marginal veins in each ear were cannulated with a quick-cath Teflon catheter (OD $0.7 \mathrm{~mm}$ ). These allowed tracer infusion through one ear vein while the other was used for repeated blood sample collection. Animals were kept in restraining cages designed to allow access to both ears during the first 90 minutes, prior to anaesthesia and abdominal section.

All experiments started 30 minutes after cannulation to allow the animals to settle down. A prime dose was administered followed by infusion of $\left[{ }^{15} \mathrm{~N}\right]$-alanine at a rate of $30 \mu \mathrm{g} / \mathrm{kg}^{-}$ ${ }^{1} \mathrm{~min}^{-1}$ and $\left[{ }^{15} \mathrm{~N}\right]$-valine of $7.5 \mu \mathrm{g} / \mathrm{kg}^{-1} \mathrm{~min}^{-1}$. The ratio of prime to infusion was 50:1 according to studies of Gilfillan et al (1985). Tracers were dissolved in isotonic sterile saline and infused at a rate of $16 \mathrm{mi} / \mathrm{h}$ for a $31 / 2 \mathrm{~h}$ period. 
Animals were anaesthetised by intravenous administration of a mixture of ketamine hydrochloride and methylparaben $(3 \mathrm{mg} / \mathrm{kg}$ ) after $2 \mathrm{~h}$ constant infusion of tracers. This was followed by abdominal section to expose uterus. The uterus was opened at the mid-line to allow the exposure of one foetus at a time. Maternal blood samples were taken simultaneously at $0,1,2,2.5$ and $3 \mathrm{~h}$ while umbilical venous followed by arterial blood were taken at 2, 2.5 and $3 \mathrm{~h}$ time points. A foetus was used for each of the time points and samples are taken with the placenta still intact with both mother and foetus.

Preparation of Samples for analysis: Blood samples were collected in chilled heparinized tubes, it was then centrifuged and the plasma separated from blood cells

Amino Acid Analysis: To an aliquot of the plasma was added equal volume of $6 \%$ suiphosalicylic acid to precipitate the protein, it was centrifuged and the filtrate was subjected to amino acid analysis to determine alanine and valine concentration using Beckman model 121 automatic amino acid analyser.

\section{GC-MS Measurements: GC-MS} measurements were performed on a Finnegan 4500 quadruple GC-MS inter-faced to an INCOS data system. The mass spectrometer was operated in the electron impact (EI) mode with isobutene as reactant gas. Measurements of isotopic abundance were made using computer controlled selected ion monitoring (SIM). The plasma amino acids were deproteinized after which they were derivatized to N-trifiuro-acetyl-n-butyl ester derivatives (Irving et al, 1978; Nissim and Lapidot, 1979).
The fragments $\mathrm{m} / \mathrm{z} 140-141$ and $168-169$ of alanine and valine respectively were analysed using the ET mode and 15 enrichments of alanine and valine were calculated from $\mathrm{m} / \mathrm{z}$ 140-141 and 168-169 respectively. Statistical analyses were carried out using either the Student T-test or the Anova one way analysis.

\section{RESULTS}

Concentrations of alanine and valine in maternal and umbilical venous and arterial blood are presented in Table 1. Over the experimental period, there was no detectable significant difference of mean $\pm S D$ of alanine concentrations within the sampling intervals in maternal, umbilical venous and arterial blood samples.

Differences in alanine concentration at various sampling time were not significant and results suggest that alanine concentration was in a steady state and the system was not being perturbed. Similar results were obtained for valine and similar conclusion drawn for alanine could be drawn for valine with respect to amino acid steady state conditions.

Comparisons of the mean \pm SD of alanine concentration in maternal and umbilical venous blood was statistically highly significant $(p<$ 0.001 ). Similar result and significant level were obtained in comparison between maternal and umbilical arterial blood. No significant difference was found between the means \pm SD of umbilical venous and arterial blood samples. Similar comparisons for valine concentration showed some differences, these were not significantly different.

The enrichment of alanine and valine in both maternal and umbilical blood are presented in Table 2.

Table 1: Concentrations of alanine and Valine in maternal and foetal blood after 3hrs of continuous infusion of a mixture of alanine and Valine. Results are means SD with ranges in parenthesis

\begin{tabular}{|c|c|c|c|c|c|}
\hline Time point & & 0.0 & 2.0 & 2.5 & 3.0 \\
\hline \multirow[t]{4}{*}{ Alanine $(\mathrm{mol} / \mathrm{ml})$} & \multirow[t]{2}{*}{ MV } & $\begin{array}{l}561.96 \pm 112.56 \\
(430-665.6)\end{array}$ & $\begin{array}{l}518.96 \pm 118.68^{\text {ab }} \\
(404.4-651.2)\end{array}$ & $\begin{array}{l}636.10 \pm 15.10^{\text {ab }} \\
(621.0-651.2)\end{array}$ & $\begin{array}{l}638.14 \pm 114.24^{\mathrm{ab}} \\
(510.6-808.2)\end{array}$ \\
\hline & & ND & $1164.6 \pm 191.73^{a}$ & $1373.6 \pm 303.3^{a}$ & $1631.67 \pm 70.21^{a}$ \\
\hline & UV & & $(998.3-1374.6)$ & $(1150.9 \pm 1719.1)$ & $(1550.9-1678.1$ \\
\hline & UA & ND & $\begin{array}{l}1169.13 \pm 253.33^{6} \\
(911.3-1417.7)\end{array}$ & $\begin{array}{l}1194.97 \pm 169.91^{b} \\
(1045.2-1379.6)\end{array}$ & $\begin{array}{l}1654.0 \pm 81.23^{b} \\
(1563.2-1719.1)\end{array}$ \\
\hline \multirow[t]{3}{*}{ Valine $(\mathrm{mol} / \mathrm{ml})$} & MV & $\begin{array}{l}284.73 \pm 67.32 \\
(229.2-359.6) \\
\end{array}$ & $\begin{array}{l}288.53 \pm 31.32 \\
(270.0-32.6)\end{array}$ & $\begin{array}{l}337.87 \pm 11.87 \\
9325.3-348.9)\end{array}$ & $\begin{array}{l}320.93 \pm 26.21 \\
(300.2-350.4)\end{array}$ \\
\hline & UV & ND & $\begin{array}{l}363.00 \pm 110.56 \\
(251.1-472.2)\end{array}$ & $\begin{array}{l}374.63 \pm 114.05 \\
(262.5-490.05)\end{array}$ & $\begin{array}{l}454.77 \pm 65.01 \\
(399.5-526)\end{array}$ \\
\hline & UA & ND & $\begin{array}{l}321.60 \pm 90.75 \\
(231.3-412.5)\end{array}$ & $\begin{array}{l}352.56 \pm 109.0 \\
(352.2-461.6)\end{array}$ & $\begin{array}{l}421.5 \pm 46.60 \\
(369.2-458.6)\end{array}$ \\
\hline
\end{tabular}

$M V=$ Maternal Venous blood; UV = Umbilical venous blood; UA = Umbilical arterial blood

$a, b=P<0.001$ comparison of MV Vs UV, MV Vs UA 
Table 2: With enrichment of ${ }^{15} \mathrm{M}$ alanine and ${ }^{15} \mathrm{~N}$ Valine of maternal and foetal plasma. Values are mean \pm SD with ranges in parenthesis after 3 hour period of infusion of the two amino acid mixtures

\begin{tabular}{|c|c|c|c|c|}
\hline Time point & 0 & 2.0 & 2.5 & 3.0 \\
\hline Alanine $(\mathrm{mol} / \mathrm{ml}) \mathrm{MV}$ & - & $\begin{array}{l}13.91 \pm 4.56 \\
(10.98-19.16) \\
\end{array}$ & $\begin{array}{l}15.48 \pm 5.81 \\
(11.38-19.59) \\
\end{array}$ & $\begin{array}{l}14.09 \pm 4.86 \\
(11.09-19.69) \\
\end{array}$ \\
\hline UV & - & $\begin{array}{l}4.24 \pm 1.51 \\
(3.50-5.98)\end{array}$ & $\begin{array}{l}1.48 \pm 0.084 \\
(4.43-4.53)\end{array}$ & $\begin{array}{l}4.75 \pm 0.80 \\
(3.95-5.56)\end{array}$ \\
\hline UA & - & $\begin{array}{l}2.62 \pm 1.09 \\
(1.87-3.86)\end{array}$ & $\begin{array}{l}2.35 \pm 0.063 \\
(1.90-2.79)^{a}\end{array}$ & $\begin{array}{l}2.74 \pm 0.92 \\
(2.01-3.78)^{a}\end{array}$ \\
\hline$\underline{U V}-V A$ & - & & & \\
\hline UV & & 38.2 & 47.52 & 42.13 \\
\hline Valine $(\mathrm{mol} / \mathrm{ml}) \quad \mathrm{MV}$ & - & $\begin{array}{l}3.67 \pm 0.68 \\
(3.02-4.38)\end{array}$ & $\begin{array}{l}3.66 \pm 0.56 \\
(3.12-4.25)\end{array}$ & $\begin{array}{l}3.82 \pm 0.49 \\
(3.37-4.35)\end{array}$ \\
\hline UV & - & $\begin{array}{l}1.40 \pm 0.07 \\
(1.32-1.46)\end{array}$ & $\begin{array}{l}1.84 \pm 0.029 \\
(1.81 \pm 1.86) \\
\end{array}$ & $\begin{array}{l}1.80 \pm 0.08 \\
(1.72-1.78)\end{array}$ \\
\hline UA & - & $\begin{array}{l}1.26 \pm 0.15 \\
(1.10-1.39)\end{array}$ & $\begin{array}{l}1.84 \pm 0.12 \\
(1.77-1.99)\end{array}$ & $\begin{array}{l}1.74 \pm 0.39 \\
(1.70-1.78)\end{array}$ \\
\hline$\underline{U V}-V A$ & & & & \\
\hline UV & - & 10 & 0 & 3 \\
\hline
\end{tabular}

During isotopic steady state in maternal compartments, the maternal steady state was achieved two hours after constant infusion and remain as such throughout the experimental period. Our result showed that the umbilical venous and the arterial blood achieved isotopic steady state throughout the experimental period as comparison of the mean $\pm S D$ of samplings show no significant difference for both alanine and valine.

Comparisons of the mean \pm SD of alanine concentration in maternal and umbilical venous blood was statistically highly significant ( $p<$ 0.001 ). Similar result and significant level were obtained in comparison between maternal and umbilical art blood. No significant difference was found between the means $\pm S D$ of umbilical venous and arterial blood samples. Similar comparisons for valine concentration showed some differences, these were not significantly different.

The enrichment of alanine and valine in both maternal and umbilical blood are presented in Table 2. During isotopic steady state in maternal compartments, the maternal steady state was achieved two hours after constant infusion and remain as such throughout the experimental period. Our result showed that the umbilical venous and the arterial blood achieved isotopic steady state throughout the experimental period as comparison of the mean \pm SD of samplings show no significant difference for both alanine and valine.

The enrichment of alanine in the umbilical venous blood was $4.24 \pm 1.51,4.45 \pm 0.64$ and $4.75 \pm 0.80$ corresponding to sampling time of $2,2.5$ and $3.0 \mathrm{~h}$ respectively, which was $68.9 \pm$ $2.4 \%$ lower than data simultaneously obtained from the maternal vein $(13.91 \pm 4.6,15.48 \pm$ 5.8 and $14.1 \pm 4.9$ ). A further decrease of 42.7 $\pm 4.7 \%$ in the umbilical arterial sample compared to umbilical venous blood. The data suggest possible fetus production of alanine in utero. Statistical comparison of the mean \pm SD of 15 enrichment of alanine between the umbilical venous and arterial blood showed a statistically significant difference $(p<0.05)$.

Data on enrichment of valine over the experimental period showed that both the maternal and foetal compartment were in isotopic steady state. Comparison of the ' enrichment of valine in the umbilical venous blood was $54.8 \pm 6.3 \%$ less than that of the maternal blood. Statistical comparison of the umbilical venous and arterial showed no significant difference. The results tend to suggest that there was no apparent valine production during the experimental period. The data presented on this table show the 15 enrichment ratio of alanine-valine in maternal and umbilical venous blood to be $4: 1$ corresponding to the ratio of infused material except for the umbilical arterial blood where this ratio has changed due to alanine dilution in the foetus.

\section{DISCUSSION}

Previous amino acid studies both in animal and human have been geared towards understanding of its production, turnover, catabolism and placenta transfers of the various amino acid both in pregnant and non pregnant animals and humans. Concentration of the various amino acids in both normal, and abnormal conditions have been studied and well defined (Gilfihlan et al, 1985; Battaglia, 
1986, Lemmon et al, 1976, Kaihan et al. 1988; Letto et al., 1986).

Most of these studies involve the administration of an amino acid with or without carbohydrate especially glucose which is a precursor to the synthesis of some of the amino acids (Gilfillan et al., 1985; Kaiham et al., 1988; van Veen et al., 1987). Studies of Gilfillan et al. (1985) suggest that alanine production which resulted in isotopic dilution in human foetus may be a result of alanine synthesis from precursors and/or protein catabolism in the muscles. This suggestion was based mostly on their results and that of Lemmons (1979) who showed that in ovine foetus amino acid catabolism do occur in vitro

We have used a mixture of amino acids, alanine a non essential and valine an essential amino acid to elucidate possible explanation.

The present studies with respect to alanine showed that a steady isotopic state can be achieved in both material and foetal compartments suggesting the possibility that the isotopic influx from the placenta to the foetus was constant throughout the experiment indicating possible non mixing or minimal mixing of the isotopical infused amino acids. Similar isotopic steady state was achieved in the case of valine. Isotopic dilution of about two folds was observed between the umbilical venous blood and arterial blood, suggesting possible endogenous alanine production which is in agreement with human studies (Gilfillan 1985) while in contrast no noticeable isotopic dilution of enrichment of valine between the umbilical venous and arterial blood, suggesting no endogenous production of valine as does alanine.

Studies of Letto (1986) and Lee and Davis (1986) using starved animals concluded that amino acid catabolism is a relatively minor pathway in supply carbon for net synthesis of alanine and glutamate and that valine is metabolised to 3 - hydroxyisoburate, therefore protein catabolism in the foetal muscle will have resulted in dilution of 15 enriched valine. The result presented does suggest that this is not the case and therefore protein catabolism do not occur and dilution observed with alanine was due to production. With respect to amino acid concentration in maternal and umbilical blood, our results are in agreement with those of Lemmons et a!. (1976) and Van Veen et a!. (1987) in foetal Lamb Palou et al (1970) in rat and Gilfillian et al (1985) in human showing that the amino acid concentrations especially the neutral amino acids are higher in the foetus than the maternal blood.

The use of amino acid mixture in this type of studies to the best of our knowledge has not been attempted and it allows us to deduce the possible mechanism of alaninie dilution.

\section{ACKNOWLEDGEMENTS}

We are grateful to Dr. Nava Nevo for technical assistance. TSE is a recipient of Sir Charles Clore fellowship.

\section{REFERENCES}

Battaglia, F.C. (1986). Placenta transport and utilization of amino acids and carbohydrates. Fed. Proc. 45, 25082512.

Trvomg. CS., Nissim, I. And Lapidot, A. (1978). The determination of amino acid pooi sixes and turnover rates by GC-MS analysis. Biomed. Mass Spectrom. 5, 17.

Nissim, I. and Lspifoy, S (1979). Plasam amino acid turnover rates and $p$ in rabbits in vivo studies using stable isotopes. Amer. N. Physiol. 6, E418.

Kaltian, S.C., Gilfillan, C.A., Tserng, KK. Y. and Savin, S.M. (1988). Glucose-alanine relationship in normal human pregnancy. Metabolism 37, $152-158$.

Gilfillian, C.A., Tserng, K. Y. and Kaihan S.C. (1985). Alanine production bu human foetus at term gestation. Biol. Neonate 47, $141-147$.

Lee, S. H.C. and Davis, E.J. (1986). Amino acid catabolism by perfused rat hindquarter: The metabolic fate of valine. Biochem. J. 233, 621 - 630 .

Lemmons, J.A., Adcock III, E.W., Jones Jr., M.D., Naughton, M.A., Meschia, G. and Battaglia, F. C. (19). Umbilical uptake of amino acids in the unstressed foetal lamb. J.. Clin. Invest. 58, 1428 - 1434.

Lemmons, J.A. (1979). Foetal-placental nitrogen metabolism Semin. Perinatol. 3, $177-190$.

Letto, J., Biosnan, M.E. and Bronsnan, J.T. (1986) Valine metaolism: Gluconeogenesis from 3 hydroxyisobutyrate. Biochem. J. 240, $909-912$.

Van Veen, L.C.P., Teng, C., Hay Jr. W.W., Meschia, G. and Battaglia, F.C. (1987). Leucine disposal and oxidation rates in foetal lamb. Metabolism 36, $48-53$.

Kahana Z and Lapidot (1983): Microbial production of L. ' Glutamic acid and GC - MS analysis. Anal. Biochem. $132160-164$.

Palou, A. Arola, L and Alemany M. (1977): Plasma amino acid concentration in pregnant rates and 21 days Foetuses. Biochem J. $16649-55$.

Freinkel, N, Metzger, B.E. Nitzan, M. Hare, J.W., Shambaugh, GG.E. Marshall, R.T., Surmaczynska B.Z and Nagal, T.G. 1972. J. Med Sci. $8426-473$.

Schneider, J. Mohien, K.H. and daneis J. (1979): Transfer of amino acids across the in vitro perfused human placenta. Pediat Res. 13, 236 - 240.

Penfold, P. Illsley N.P., Purkiss, P. and Jennings P. (1983) Human placental amino acid transfer and metabolism in oxygenated and anoxi conditions. Trophoblast Research 1, 27-36.

Eaton B.M., Mann, G.E. and Yudilevich DZ. (1982): Transport specificity for neutral and basic amino acids at maternal and foetal interfaces of the guinea pig placenta. Amer. J. Obst and Ayn 101820 - 829.

Received: September 2002 Accepted: June 2003 